\title{
The impact of multidisciplinary team conferences in urologic cancer in a tertiary hospital
}

\author{
Miguel Gil ${ }^{1}$. João Guerra ${ }^{1} \cdot$ Vanessa Andrade $^{1} \cdot$ Mariana Medeiros $^{1} \cdot$ Thiago Guimarães $^{1} \cdot$ Rui Bernardino $^{1}$. \\ Gil Falcão $^{1} \cdot$ Fernando Calais da Silva $^{1} \cdot$ Luís Campos Pinheiro' $^{1}$
}

Received: 15 June 2020 / Accepted: 10 August 2020 / Published online: 20 August 2020

○) Springer Nature B.V. 2020

\begin{abstract}
Purpose Multidisciplinary team (MDT) conferences are currently the standard of care in cancer patients' management. Despite evidence supporting benefits to the majority of malignancies, a paucity of data exists examining the impact in urinary and male genital cancers. This study aims to evaluate the impact of MDT conferences in urologic cancer practice. Methods Clinical plans discussed in urologic MDT conferences in Centro Hospitalar Universitário de Lisboa Central between January 2019 and December 2019 were retrospectively analysed. Clinical plans were categorized as accepted, changed, rejected (cases that had to be re-presented to the MDT because of insufficient staging or administrative issues) or no plan. MDT conferences' impact was assessed according to type of consultation, referral medical specialty and primary tumour type. Results 710 clinical plans were discussed at the MDT conferences. $61.8 \%$ were accepted, $10.6 \%$ were changed, $16.5 \%$ were rejected and $11.1 \%$ of cases referred to MDT discussion had no defined clinical plan. First consultations had a higher rate of accepted clinical plans (63.4\%) versus subsequent consultations (56.4\%). Referrals by the urology specialty had the highest rate of acceptances (64.3\%). On the stratification by primary tumour site, testicular cancer had the highest acceptance rate (70.3\%), whereas bladder cancer had the lowest (47.8\%).

Conclusions MDT conferences had an important impact in the management of $38.2 \%$ of cases. Therefore, all patients with urologic malignancies should be referred to MDT review to ensure optimal clinical care.
\end{abstract}

Keywords Multidisciplinary team $\cdot$ Multidisciplinary conference $\cdot$ Urologic cancer $\cdot$ Decision-making

\section{Introduction}

Cancer is one of the leading causes of death worldwide. With the population ageing, urologic cancer burden has been increasing in the last decades [1]. It is estimated that urinary and male genital malignancies together will be responsible for $20.1 \%$ of new cancer cases and $11.2 \%$ of cancer deaths in the USA in 2020 [2].

Cancer patients' decision-making is a complex process. It has been recognised in recent years that a multidisciplinary approach is important to ensure optimal quality of care. Multidisciplinary team (MDT) conferences serve not only to guide one's management, but also to ensure the adherence to

Miguel Gil

miguelgil@campus.ul.pt

1 Urology Department, Centro Hospitalar Universitário de Lisboa Central, EPE, Rua José António Serrano, 1150-199 Lisbon, Portugal the latest clinical guidelines and its implementation taking into account the local context [3]. However, there is no consensus about which patients should be reviewed by an MDT [3]. In some centres, all patients are referred to an MDT evaluation, while in others only selected complex cases are discussed. Moreover, implementation of MDT conferences differs worldwide. Whereas in the UK and in France it is mandatory to review all new cases of cancer by an MDT, in other countries such as the USA and Australia MDT conferences have just recently gained popularity [4].

The most recent systematic review of the impact of MDT conferences on oncologic patients, which included 27 studies of all types of malignancies, found that between 4 and $35 \%$ of patients underwent changes in assessment or diagnosis and that between 2 and $52 \%$ had their management plan altered [5]. Nonetheless, there is little evidence regarding the value of MDT conferences on urologic cancer patients. The first study in urological cancer by Acher et al. found that in over $98 \%$ of patients, the MDT conferences did not 
change clinical management [6]. On the contrary, Kurpad et al. concluded that only $35 \%$ of cases had no change in either diagnosis or treatment and Rao et al. found that in $27 \%$ of patients the MDT conferences made a high impact change $[7,8]$. Likewise, $41 \%$ of cases had their management plan altered following MDT conferences in another study [9]. These studies have conflicting results regarding the patients that benefit the most from MDT discussion. While in one study it was found that changes were mainly in bladder and renal cancer patients and were less common in testicular and prostate cancer, in another study the results were exactly the opposite [7, 9].

The aim of this study was to evaluate the impact of MDT conferences in urologic cancer in a large cohort of patients to clarify the conflicting results in the literature.

\section{Patients and methods}

This was a retrospective, observational and descriptive study. All patients discussed in urologic MDT conferences between January 2019 and December 2019 in Centro Hospitalar Universitário de Lisboa Central (CHULC) were analysed. None of the patients were excluded.

The CHULC urologic MDT was founded in 2010 and meet once a week to discuss urinary and male genital cancer patients. At least a urologist, a medical oncologist, a radiologist, a radiation oncologist and a pathologist are present in each conference. All newly diagnosed cases of cancer are discussed with the exception of non-muscle-invasive bladder cancer. In addition, many patients subjected to prior treatment or of high complexity are re-referred to evaluation of the new situation.

Two groups of variables were collected: covariates (demographics, type of consultation, referral specialty and primary cancer type) and outcomes (MDT conference decision). All data were collected from the digital clinical records.

The original clinical plan proposed by the individual patient physician was compared with the consensus plan of the MDT. The outcomes were categorized as follows:

- Accepted: If the MDT endorsed the original clinical plan.

- Changed: If the MDT changed the clinical plan (e.g. change from surgery to radiotherapy or modification of the surgical strategy like adding lymphadenectomy).

- Rejected: If the MDT rejected the original clinical plan and it had to be re-presented to the MDT. Rejected clinical plans were further subdivided into two groups: rejection because of insufficient staging (e.g. renal cancer being proposed to radical nephrectomy without a thoracic computed tomography); or rejection due to administrative issues (e.g. computed tomography made in another hospital and images not accessible for review during the MDT conference).

- No plan: Cases without a defined management plan. They were further subdivided into two groups: patients referenced to MDT conference for imaging revision of dubious cases; or cases of high complexity referred to MDT conference for discussion and formulation of a management plan.

Furthermore, outcomes were analysed according to:

- First or subsequent consultation: If a patient was discussed in a subsequent MDT conference being in the same clinical situation (e.g. insufficient information available in the first conference), it was considered as a subsequent consultation. However, if a patient was discussed in more than one MDT conference for different reasons (e.g. before surgery with curative intent and after recurrence), the successive consultation was considered as a first consultation.

- Referral medical specialty: These included urology, medical oncology, internal medicine or others. For the urology specialty, a further analysis regarding the impact of the referral physician being a urology resident versus a urology attending physician was also made.

- Primary cancer type: These included prostate, renal, upper urinary tract, bladder, penile, testicular or others. Staging was also recorded for each cancer type. Where applicable, the definitions used (e.g. residual disease after radical prostatectomy) are from the European Association of Urology's guidelines [10].

Finally, for the subgroup of patients whose initial clinical plan was changed, a thorough descriptive analysis was also done.

\section{Results}

During the study period (12 months), 501 patients were discussed at the MDT weekly conferences with a median age of 71.2 years (interquartile range of 12.4 years) and a predominance of males (86.6\%) compared to females (13.4\%). There were 50 MDT conferences and a total of 710 clinical plans discussed. The distribution of cases by primary cancer sites was as follows: 390 prostate (54.9\%), 138 renal (19.4\%), 35 upper urothelial tract (4.9\%), 90 bladder (12.7\%), 13 penile (1.8\%), 37 testicular (5.2\%) and 7 others (1.0\%). 439 clinical plans $(61.8 \%)$ were accepted, $75(10.6 \%)$ were changed, $117(16.5 \%)$ were rejected and had to be re-presented to the MDT (70 [9.9\%] because of insufficient staging and 47 [6.6\%] because of administrative issues) and 79 cases (11.1\%) referred to MDT conferences had no defined clinical 
plan $(21$ [3.0\%] were referenced to imaging review and 58 [8.2\%] were cases of special high complexity referred to discussion).

$78.0 \%$ of MDT discussions were first consultations, while the remaining $22.0 \%$ were subsequent consultations. On the analysis made as a function of the type of consultation (Table 1), first consultations had a higher rate of accepted and rejected clinical plans (63.4\% and $17.3 \%$, respectively) versus subsequent consultations $(56.4 \%$ and $13.5 \%$, respectively). Conversely, first consultations had a lower rate of changed clinical plans $(9.9 \%)$ and referrals with no plan (9.4\%) compared to subsequent consultations (12.8\% and $17.3 \%$, respectively).

The urology specialty referred 652 cases to the MDT conferences, representing the vast majority of referrals $(91.8 \%)$. The remaining patients were referenced as follows: 51 cases by the medical oncology specialty $(7.2 \%), 6$ by internal medicine $(0.8 \%)$ and 1 case by orthopaedics $(0.1 \%)$. Table 2 presents the distribution of MDT conference decisions according to the referral specialty. Specialties other than urology had a lower rate of clinical plan acceptance (33.3\% [medical oncology] and $50.0 \%$ [internal medicine] versus $64.3 \%$ [urology]) and a very high rate of referrals with no defined clinical plan (47.1\% [medical oncology] and 50.0\% [internal medicine] versus $7.8 \%$ [urology]). Regarding the sub-analysis of the urology practitioners (urology residents versus senior urologists), we concluded that residents (291 cases; $44.6 \%$ of urology clinical plans) had exactly the same acceptance rate $(64.3 \%)$ as senior urologists (361 cases; $55.4 \%$ of urology clinical plans). Nevertheless, the balance between changed or rejected clinical plans and referrals with no plan was different: whereas resident clinical plans had a changing rate of $14.1 \%$, a rejection rate of $17.9 \%$ and a no plan rate of $3.8 \%$, attending physician clinical plans had rates of $8.3 \%, 16.3 \%$ and $11.1 \%$, respectively.

On the stratification by primary tumour site, testicular cancer had the highest acceptance rate (70.3\%), followed by renal cancer (68.8\%), upper urinary tract cancer (65.7\%), prostate and penis cancer (both with 61.5\%), other cancers/ diseases $(57.1 \%)$ and bladder cancer (47.8\%). Bladder cancer patients had their clinical plans changed more often by the MDT (18.9\%), followed by prostate cancer (11.5\%), testicular cancer $(8.1 \%)$, penis cancer $(7.7 \%)$, renal cancer (5.8\%) and upper urinary tract cancer $(2.9 \%)$. Regarding the rejection rate, all tumours had similar rates (between 15.4 and $16.7 \%$ ) with the exceptions of testicular and upper urinary tract cancers ( $8.1 \%$ and $28.6 \%$, respectively). Regarding the patients referred with no defined clinical plan, the group of other cancers/diseases had the highest rate (28.6\%) and upper urinary tract cancer the lowest rate $(2.9 \%)$. The remaining cancer types had no plan rates between 8.7 and $16.7 \%$. The distribution of rejections by the two main groups (insufficient staging or administrative issues) and the distribution of referrals with no plan (imaging review or for discussion) is presented on Table 3. On the same table, the distribution of the MDT consensus decisions by staging for each cancer type is shown.

Table 4 presents the main reasons for changing the original clinical plan. For prostate cancer patients, the main reason was change of surgery type (19 cases whose clinical plan was radical prostatectomy without lymphadenectomy and whose MDT consensus decision was in favour

Table 1 Impact of MDT conferences on original clinical plans according to the type of consultation

\begin{tabular}{|c|c|c|c|c|c|c|c|}
\hline \multirow[t]{2}{*}{ Type of consultation } & \multirow[t]{2}{*}{ Accepted } & \multirow[t]{2}{*}{ Changed } & \multicolumn{2}{|l|}{ Rejected } & \multicolumn{2}{|l|}{ No plan } & \multirow[t]{2}{*}{ Total } \\
\hline & & & Insufficient staging & Administrative issues & Imaging review & For discussion & \\
\hline First & $351(63.4 \%)$ & $55(9.9 \%)$ & $58(10.4 \%)$ & $38(6.9 \%)$ & $17(3.1 \%)$ & $35(6.3 \%)$ & 554 \\
\hline Subsequent & $88(56.4 \%)$ & $20(12.8 \%)$ & $12(7.7 \%)$ & $9(5.8 \%)$ & $4(2.6 \%)$ & $23(14.7 \%)$ & 156 \\
\hline Total & $439(61.8 \%)$ & $75(10.6 \%)$ & $70(9.9 \%)$ & $47(6.6 \%)$ & $21(3.0 \%)$ & $58(8.2 \%)$ & 710 \\
\hline
\end{tabular}

Table 2 Impact of MDT conferences on original clinical plans according to referral specialty

\begin{tabular}{|c|c|c|c|c|c|c|c|}
\hline \multirow[t]{2}{*}{ Referral specialty } & \multirow[t]{2}{*}{ Accepted } & \multirow[t]{2}{*}{ Changed } & \multicolumn{2}{|l|}{ Rejected } & \multicolumn{2}{|l|}{ No plan } & \multirow[t]{2}{*}{ Total } \\
\hline & & & Insufficient staging & Administrative issues & Imaging review & For discussion & \\
\hline Urology & $419(64.3 \%)$ & $71(10.9 \%)$ & $67(10.3 \%)$ & $44(6.7 \%)$ & $12(1.8 \%)$ & $39(6.0 \%)$ & 652 \\
\hline Resident & $187(64.3 \%)$ & $41(14.1 \%)$ & $32(11.0 \%)$ & $20(6.9 \%)$ & $2(0.7 \%)$ & $9(3.1 \%)$ & 291 \\
\hline Attending physician & $232(64.3 \%)$ & $30(8.3 \%)$ & $35(9.7 \%)$ & $24(6.6 \%)$ & $10(2.8 \%)$ & $30(8.3 \%)$ & 361 \\
\hline Medical oncology & $17(33.3 \%)$ & $4(7.8 \%)$ & $3(5.9 \%)$ & $3(5.9 \%)$ & $9(17.6 \%)$ & $15(29.4 \%)$ & 51 \\
\hline Internal medicine & $3(50.0 \%)$ & 0 & 0 & 0 & 0 & $3(50.0 \%)$ & 6 \\
\hline Others & 0 & 0 & 0 & 0 & 0 & $1(100.0 \%)$ & 1 \\
\hline Total & $439(61.8 \%)$ & $75(10.6 \%)$ & $70(9.9 \%)$ & $47(6.6 \%)$ & $21(3.0 \%)$ & $58(8.2 \%)$ & 710 \\
\hline
\end{tabular}


Table 3 Impact of MDT conferences on original clinical plans according to primary tumour site

\begin{tabular}{|c|c|c|c|c|c|c|c|}
\hline & \multirow[t]{2}{*}{ Accepted } & \multirow[t]{2}{*}{ Changed } & \multicolumn{2}{|l|}{ Rejected } & \multicolumn{2}{|l|}{ No plan } & \multirow[t]{2}{*}{ Total } \\
\hline & & & Insufficient staging & Administrative issues & Imaging review & For discussion & \\
\hline \multicolumn{8}{|l|}{ Prostate } \\
\hline $\begin{array}{l}\text { Localized or locally advanced } \\
\text { disease }\end{array}$ & $147(63.6 \%)$ & $29(12.6 \%)$ & $20(8.7 \%)$ & $20(8.7 \%)$ & $4(1.7 \%)$ & $11(4.8 \%)$ & 231 \\
\hline $\begin{array}{l}\text { High risk of relapse or } \\
\text { residual disease after radical } \\
\text { prostatectomy }\end{array}$ & $20(95.2 \%)$ & $1(4.8 \%)$ & 0 & 0 & 0 & 0 & 21 \\
\hline $\begin{array}{l}\text { Biochemical, local or regional } \\
\text { ganglionar relapse }\end{array}$ & $24(51.1 \%)$ & $4(8.6 \%)$ & $10(21.3 \%)$ & 0 & 0 & $9(19.1 \%)$ & 47 \\
\hline $\begin{array}{l}\text { Metastatic disease in a first- } \\
\text { line setting }\end{array}$ & $19(52.8 \%)$ & $6(16.7 \%)$ & 0 & $1(2.8 \%)$ & $2(5.6 \%)$ & $8(22.2 \%)$ & 36 \\
\hline $\begin{array}{l}\text { Castration-resistant disease } \\
\text { (metastatic or non-meta- } \\
\text { static) }\end{array}$ & $29(58.0 \%)$ & $5(10.0 \%)$ & $10(20.0 \%)$ & $2(4.0 \%)$ & $2(4.0 \%)$ & $2(4.0 \%)$ & 50 \\
\hline $\begin{array}{l}\text { Metastatic disease resistant } \\
\text { to 2nd line hormonotherapy } \\
\text { and/or resistant to chemo- } \\
\text { therapy }\end{array}$ & $1(20.0 \%)$ & 0 & 0 & 0 & $3(60.0 \%)$ & $1(20.0 \%)$ & 5 \\
\hline Subtotal & $240(61.5 \%)$ & $45(11.5 \%)$ & $40(10.3 \%)$ & $23(5.9 \%)$ & $11(2.8 \%)$ & $31(7.9 \%)$ & 390 \\
\hline \multicolumn{8}{|l|}{ Renal } \\
\hline $\begin{array}{l}\text { Renal tumour stages I, II or } \\
\text { III (from TNM staging clas- } \\
\text { sification) }\end{array}$ & $72(70.6 \%)$ & $5(4.9 \%)$ & $11(10.8 \%)$ & $6(5.9 \%)$ & 0 & $8(7.8 \%)$ & 102 \\
\hline $\begin{array}{l}\text { More than } 1 \text { renal tumour in } \\
\text { the same kidney or in each } \\
\text { kidney }\end{array}$ & $8(61.5 \%)$ & $1(7.7 \%)$ & 0 & $1(7.7 \%)$ & $1(7.7 \%)$ & $2(15.4 \%)$ & 13 \\
\hline $\begin{array}{l}\text { Status post-radical nephrec- } \\
\text { tomy with or without } \\
\text { suspicion of relapse }\end{array}$ & $8(61.5 \%)$ & $2(15.4 \%)$ & $2(15.4 \%)$ & 0 & $1(7.7 \%)$ & 0 & 13 \\
\hline $\begin{array}{l}\text { Metastatic disease in a first- } \\
\text { line setting or after radical } \\
\text { nephrectomy }\end{array}$ & $7(70.0 \%)$ & 0 & $2(20.0 \%)$ & $1(10.0 \%)$ & 0 & 0 & 10 \\
\hline Subtotal & $95(68.8 \%)$ & $8(5.8 \%)$ & $15(10.9 \%)$ & $8(5.8 \%)$ & $2(1.4 \%)$ & $10(7.2 \%)$ & 138 \\
\hline \multicolumn{8}{|l|}{ Upper urinary tract } \\
\hline $\begin{array}{l}\text { Localized upper urinary tract } \\
\text { urothelial carcinoma }\end{array}$ & $17(65.4 \%)$ & $1(3.8 \%)$ & $4(15.4 \%)$ & $3(11.5 \%)$ & 0 & $1(3.8 \%)$ & 26 \\
\hline $\begin{array}{l}\text { Status post-radical nephro- } \\
\text { ureterectomy with residual } \\
\text { disease or suspicion of } \\
\text { relapse }\end{array}$ & $5(62.5 \%)$ & 0 & $3(37.5 \%)$ & 0 & 0 & 0 & 8 \\
\hline $\begin{array}{l}\text { Metastatic upper urinary tract } \\
\text { urothelial carcinoma }\end{array}$ & $1(100.0 \%)$ & 0 & 0 & 0 & 0 & 0 & 1 \\
\hline Subtotal & $23(65.7 \%)$ & $1(2.9 \%)$ & $7(20.0 \%)$ & $3(8.6 \%)$ & 0 & $1(2.9 \%)$ & 35 \\
\hline \multicolumn{8}{|l|}{ Bladder } \\
\hline $\begin{array}{l}\text { High-risk non-muscle- } \\
\text { invasive or non-metastatic } \\
\text { muscle-invasive bladder } \\
\text { cancer }\end{array}$ & $32(60.4 \%)$ & $10(18.9 \%)$ & $2(3.8 \%)$ & $8(15.1 \%)$ & $1(1.9 \%)$ & 0 & 53 \\
\hline $\begin{array}{l}\text { Residual disease or suspicion } \\
\text { of relapse after radical } \\
\text { cystectomy }\end{array}$ & $7(50.0 \%)$ & $2(14.3 \%)$ & $2(14.3 \%)$ & $1(7.1 \%)$ & $2(14.3 \%)$ & 0 & 14 \\
\hline Metastatic bladder cancer & $4(17.4 \%)$ & $5(21.7 \%)$ & $1(4.3 \%)$ & $1(4.3 \%)$ & $2(8.7 \%)$ & $10(43.5 \%)$ & 23 \\
\hline Subtotal & $43(47.8 \%)$ & $17(18.9 \%)$ & $5(5.6 \%)$ & $10(11.1 \%)$ & $5(5.6 \%)$ & $10(11.1 \%)$ & 90 \\
\hline \multicolumn{8}{|l|}{ Penis } \\
\hline Non-metastatic penile cancer & $7(63.6 \%)$ & $1(9.1 \%)$ & $1(9.1 \%)$ & $1(9.1 \%)$ & 0 & $1(9.1 \%)$ & 11 \\
\hline
\end{tabular}


Table 3 (continued)

\begin{tabular}{|c|c|c|c|c|c|c|c|}
\hline & \multirow[t]{2}{*}{ Accepted } & \multirow[t]{2}{*}{ Changed } & \multicolumn{2}{|l|}{ Rejected } & \multicolumn{2}{|l|}{ No plan } & \multirow[t]{2}{*}{ Total } \\
\hline & & & Insufficient staging & Administrative issues & Imaging review & For discussion & \\
\hline Metastatic penile cancer & $1(50.0 \%)$ & 0 & 0 & 0 & $1(50.0 \%)$ & 0 & 2 \\
\hline Subtotal & $8(61.5 \%)$ & $1(7.7 \%)$ & $1(7.7 \%)$ & $1(7.7 \%)$ & $1(7.7 \%)$ & $1(7.7 \%)$ & 13 \\
\hline \multicolumn{8}{|l|}{ Testis } \\
\hline Testis neoplasm & $14(87.5 \%)$ & 0 & $1(6.3 \%)$ & 0 & 0 & $1(6.3 \%)$ & 16 \\
\hline $\begin{array}{l}\text { Status post-orchiectomy with } \\
\text { or without suspicion of } \\
\text { relapse }\end{array}$ & $12(57.1 \%)$ & $3(14.3 \%)$ & $1(4.8 \%)$ & $1(4.8 \%)$ & $1(4.8 \%)$ & $3(14.3 \%)$ & 21 \\
\hline Subtotal & $26(70.3 \%)$ & $3(8.1 \%)$ & $2(5.4 \%)$ & $1(2.7 \%)$ & $1(2.7 \%)$ & $4(10.8 \%)$ & 37 \\
\hline \multicolumn{8}{|l|}{ Others } \\
\hline Urachal carcinoma & $2(100.0 \%)$ & 0 & 0 & 0 & 0 & 0 & 2 \\
\hline Non-oncologic disease & 0 & 0 & 0 & $1(100.0 \%)$ & 0 & 0 & 1 \\
\hline Adrenal neoplasm & $1(100.0 \%)$ & 0 & 0 & 0 & 0 & 0 & 1 \\
\hline $\begin{array}{l}\text { Proximal ureter obstruction } \\
\text { by pancreatic cancer }\end{array}$ & 0 & 0 & 0 & 0 & 0 & $1(100.0 \%)$ & 1 \\
\hline $\begin{array}{l}\text { Metastatic primary mediasti- } \\
\text { nal germ cell tumour }\end{array}$ & $1(50.0 \%)$ & 0 & 0 & 0 & $1(50.0 \%)$ & 0 & 2 \\
\hline Subtotal & $4(57.1 \%)$ & 0 & 0 & $1(14.3 \%)$ & $1(14.3 \%)$ & $1(14.3 \%)$ & 7 \\
\hline Total & $439(61.8 \%)$ & $75(10.6 \%)$ & $70(9.9 \%)$ & $47(6.6 \%)$ & $21(3.0 \%)$ & $58(8.2 \%)$ & 710 \\
\hline
\end{tabular}

Table 4 Reasons for changing original clinical plans

\begin{tabular}{|c|c|c|c|c|c|c|c|c|}
\hline & Prostate & Renal & Upper urinary tract & Bladder & Penis & Testis & Others & Total \\
\hline $\begin{array}{l}\text { Switch from surgical to noninvasive } \\
\text { treatment }\end{array}$ & $3(6.7 \%)$ & 0 & 0 & $1(5.9 \%)$ & 0 & 0 & 0 & $4(5.3 \%)$ \\
\hline $\begin{array}{l}\text { Switch from noninvasive to surgical } \\
\text { treatment }\end{array}$ & $4(8.9 \%)$ & 0 & 0 & 0 & 0 & 0 & 0 & $4(5.3 \%)$ \\
\hline Switch from treatment to no treatment & 0 & $3(37.5 \%)$ & 0 & $3(17.6 \%)$ & 0 & $1(33.3 \%)$ & 0 & $7(9.3 \%)$ \\
\hline Switch from no treatment to treatment & 0 & $2(25.0 \%)$ & 0 & $1(5.9 \%)$ & 0 & $1(33.3 \%)$ & 0 & $4(5.3 \%)$ \\
\hline $\begin{array}{l}\text { Addition or subtraction of a treatment } \\
\text { modality to the overall treatment plan }\end{array}$ & $5(11.1 \%)$ & 0 & 0 & $6(35.3 \%)$ & 0 & 0 & 0 & $11(14.7 \%)$ \\
\hline $\begin{array}{l}\text { Change in treatment plan due to re- } \\
\text { interpretation of imaging findings }\end{array}$ & 0 & $2(25.0 \%)$ & $1(100.0 \%)$ & $3(17.6 \%)$ & 0 & 0 & 0 & $6(8.0 \%)$ \\
\hline $\begin{array}{l}\text { Change of noninvasive treatment modal- } \\
\text { ity }\end{array}$ & $10(22.2 \%)$ & 0 & 0 & $2(11.8 \%)$ & 0 & 0 & 0 & $12(16.0 \%)$ \\
\hline Change of surgery type & $21(46.7 \%)$ & 0 & 0 & $1(5.9 \%)$ & $1(100.0 \%)$ & 0 & 0 & $23(30.7 \%)$ \\
\hline Others & $2(4.4 \%)$ & $1(12.5 \%)$ & 0 & 0 & 0 & $1(33.3 \%)$ & 0 & $4(5.3 \%)$ \\
\hline Total & 45 & 8 & 1 & 17 & 1 & 3 & 0 & 75 \\
\hline
\end{tabular}

of lymphadenectomy be performed; and 2 opposite cases). Regarding bladder cancer, addition or subtraction of a treatment modality to the overall treatment plan was the main reason for change with six cases: in five occasions neoadjuvant treatment was added or subtracted to radical cystectomy and in one case chemotherapy was added to external radiotherapy. In the remaining primary cancer types, there was a lower number of changed clinical plans and there was not a preponderance of one reason over the others.

\section{Discussion}

Genitourinary malignancies are a heterogenous group with different incidences and prognosis and whose management is not always straightforward. There are many treatment modalities, and novel approaches have emerged recently. Therefore, the existence of a multidisciplinary team with expertise in these types of tumours is an invaluable contribute to the management of these patients. 
To the best of our knowledge, this is the largest study of the impact of MDT conferences in urologic cancer patients (all the available studies in the literature had less than 300 patients) and one of the largest studies considering all types of malignancies.

In our study, $61.8 \%$ of clinical plans were accepted, whereas the remaining $38.2 \%$ of cases had their management altered by the MDT: $10.6 \%$ of clinical plans were changed, $16.5 \%$ were rejected and had to be re-presented to the MDT and $11.1 \%$ of cases were referred to MDT discussion with no defined clinical plan. These results were similar to the results obtained by El Khoury et al. in which the MDT altered the management decisions in $40.7 \%$ of cases [9]. However, there is an important discrepancy in the results of the remaining published studies that assessed the impact of MDT conferences in urologic cancer patients, with percentages of alteration of management plans ranging from 1.6 to $65.4 \%[6,7]$.

In our series, $10.6 \%$ of clinical plans were changed by the MDT. These are the cases in which after careful revision of patient data and records, the MDT decided that a different plan would be more suitable than the initial plan formulated by the individual patient physician. In our centre, the MDT follows the guidelines from the European Association of Urology, taking into consideration the local context and the individual patient particularities.

The remaining clinical plans that were not accepted were rejected $(16.5 \%)$ or had no defined clinical plan (11.1\%). Clinical plans were rejected because of insufficient staging or administrative issues $(9.9 \%$ and $6.6 \%$ of all clinical plans, respectively). As insufficient staging occurred mainly because of delay in getting the exams ready to discuss in MDT conferences we may consider that insufficient staging and administrative issues are preventable reasons and represent an opportunity for improvement in the future. Furthermore, these facts demonstrate the essential role of MDT conferences in auditing cancer management in our centre and in guaranteeing the adherence to the latest guidelines and to the best standards of care. It is noteworthy that in the only study besides ours that reported the percentage of patients requiring further work-up before a decision could be made, the results (10.4\%) were similar [7]. In the same study, Kurpad et al. reported that $17.1 \%$ of cases were referred to MDT conference for discussion without requiring a decision on a proposal, whilst in our study the proportion of patients referenced with no clinical plan was lower (11.1\%) [7].

Surprisingly, during the study period the proportion of accepted clinical plans was higher in first consultations (63.4\%) versus subsequent consultations (56.4\%). Subsequent consultations represent the cases in which there was the need of more than one consultation to reach a consensus plan. As a consequence, we would expect that in subsequent consultations, given that more information is available and that the patients had already been discussed previously, the acceptance rate would be superior to first consultations, contrary to our findings. This was due to a significant proportion of subsequent consultations be referred with no plan, probably by being complex cases.

This is the first study that evaluated if the MDT impact depends upon the specialty that formulates the initial clinical plan and proposes the patient to MDT conference discussion. The great majority of clinical plans were made by urology physicians and had a higher rate of acceptance (64.3\%) compared to medical oncology (33.3\%). This might have been due to the fact that while urology specialty in our centre refers all newly diagnosed cancer patients to the MDT weekly conferences despite the management of many of them being straightforward, medical oncology only refers selected cases. Interestingly, regarding the urology specialty, clinical plans made by residents had exactly the same acceptance rate $(64.3 \%)$ as clinical plans made by attending physicians. Probably, the postgraduation and the continued medical education taken together by residents and senior urologists are responsible for these similar acceptance rates between different medical generations.

Discrepancies between published studies occur when stratifying the impact of MDT conferences by primary tumour site. In our cohort, bladder cancer had the lowest rate of clinical plan acceptance $(47.8 \%)$. One possible explanation is the fact that low-risk non-muscle-invasive bladder tumours usually are not referred to MDT review in our centre and consequently only high-risk or muscle-invasive tumours are referred whose management is complex with multiple possibilities of treatment. Contrary to El Khoury et al. and Kurpad et al. studies in which testicular cancer had the highest rates of management alteration by MDT conferences $(57.1 \%$ and $71.5 \%$ [considering cases requiring further diagnostic work-up], respectively), in our cohort testicular cancer clinical plans had the highest acceptance rate $(70.3 \%)$ $[7,9]$. These differences might reflect the heterogeneity of cases that are referred to MDT conferences between centres.

Another controversy regarding urologic MDT conferences is whether or not the impact of MDT review depends on the disease staging. While in Kurpad et al. the impact appeared to be greatest for lower stage disease, in Rao et al. metastatic disease management was shown to change more often $[7,8]$. In our study, we found that the impact of staging depends on the primary site of tumour: whereas for prostate and bladder cancer advanced disease is associated with lower rates of clinical plan acceptance, for renal cancer there was no difference. The higher rates of referrals with no plan are the main reason for the lower rates of acceptance in advanced disease stages. This can be explained by the fact that these cases are usually more complex or dubious.

Our study has many limitations, namely, the inherent limitations to a unicentric and retrospective study. Moreover, the MDT is not blinded and has access to the initial clinical 
plan, representing a potential bias. Additionally, our study does not assess the compliance and the implementation of the MDT consensus plans and whether or not these improved patients' actual outcomes (e.g. overall survival).

In conclusion, a multidisciplinary approach to urinary and male genital cancer is of value for these patients' clinical care. In our study, MDT conferences had an important impact in the management of $38.2 \%$ of cases. Bladder cancer patients were the most affected with roughly half of cases having their clinical plans altered. However, even in the less affected tumour (testicular), MDT significantly impacted almost one-third of cases. Consequently, all patients with urologic malignancies, irrespective of cancer type or staging, should be referred to MDT review.

Funding No financial support was provided.

\section{Compliance with ethical standards}

Conflict of interest The authors report no conflict of interest.

Ethical approval The study was conducted according to the ethical principles of the Declaration of Helsinki.

\section{References}

1. Dy GW, Gore JL, Forouzanfar MH, Naghavi M, Fitzmaurice C (2017) Global burden of urologic cancers, 1990-2013. Eur Urol 71(3):437-446
2. Siegel RL, Miller KD, Jemal A (2020) Cancer statistics. CA Cancer J Clin 70(1):7-30

3. Iyer NG, Chua MLK (2019) Multidisciplinary team meetingschallenges of implementation science. Nat Rev Clin Oncol 16(4):205-206

4. Sevdalis N, Green JSA (2014) Expanding the evidence for multidisciplinary team cancer care. Nat Rev Urol 11(12):668-669

5. Pillay B, Wootten AC, Crowe H, Corcoran N, Tran B, Bowden $P$ et al (2016) The impact of multidisciplinary team meetings on patient assessment, management and outcomes in oncology settings: a systematic review of the literature. Cancer Treat Rev 42:56-72

6. Acher PL, Young AJ, Etherington-Foy R, McCahy PJ, Deane AM (2005) Improving outcomes in urological cancers: the impact of "multidisciplinary team meetings". Int J Surg 3(2):121-123

7. Kurpad R, Kim W, Rathmell WK, Godley P, Whang Y, Fielding $\mathrm{J}$ et al (2011) A multidisciplinary approach to the management of urologic malignancies: does it influence diagnostic and treatment decisions? Urol Oncol Semin Orig Investig 29(4):378-382

8. Rao K, Manya K, Azad A, Lawrentschuk N, Bolton D, Davis ID et al (2014) Uro-oncology multidisciplinary meetings at an Australian tertiary referral centre-impact on clinical decisionmaking and implications for patient inclusion. BJU Int 114(Supplement 1):50-54

9. El Khoury R, Chahrouri M, Hachem C, Abi Zeid J, El Alam P, Abdessater M (2016) Evaluation of multidisciplinary team meetings in uro-oncology. Leban Med J 64(2):84-90

10. EAU (2020) EAU guidelines. EAU Guidelines Office, Arnhem

Publisher's Note Springer Nature remains neutral with regard to jurisdictional claims in published maps and institutional affiliations. 